\title{
A genome-wide analysis of colorectal cancer in a child with Noonan syndrome
}

\author{
Rahul M Prasad ${ }^{1,2^{\star}}$, Rajen J Mody ${ }^{2}$, George Myers ${ }^{3}$, Melisa Mullins ${ }^{3}$, Zaher Naji ${ }^{3}$, James \\ D Geiger $^{4}$
}

${ }^{1}$ The University of Toledo College of Medicine and Life Sciences, Toledo, Ohio

${ }^{2}$ Division of Pediatric Hematology/Oncology, Department of Pediatrics, C.S. Mott Children's

Hospital, University of Michigan, Ann Arbor, Michigan, rmody@med.umich.edu

${ }^{3}$ Mercy St. Vincent Medical Center, Toledo, Ohio

${ }^{4}$ Section of Pediatric Surgery, Department of Surgery, C.S. Mott Children's Hospital,

University of Michigan, Ann Arbor, Michigan jgeiger@med.umich.edu

* Correspondence to:

Rahul Prasad, D4207, Medical Professional Building, University of Michigan, 1500 East

Medical Center Drive, Ann Arbor, MI 48109-5718. Email: 09prasad@gmail.com

Text word count 1,199;

Abstract word count: 98;

Tables: 1

Figures: 1

Key words: Noonan syndrome; Pediatric hematology/oncology; Molecular genetics; Tumors, solid; Rare tumors

\begin{tabular}{|l|l|}
\hline Abbreviation & Full term/phrase \\
\hline CRC & Colorectal cancer \\
\hline NS & Noonan syndrome \\
\hline FAP & Familial adenomatous polyposis \\
\hline HNPCC & Hereditary non-polyposis colorectal cancer \\
\hline NF1 & Neurofibromatosis 1 \\
\hline MUTYH & Mut Y DNA glycosylase gene \\
\hline KRAS & KRAS proto-oncogene, GTPase \\
\hline BRAF & $\begin{array}{l}\text { B-RAF proto-oncogene serine/threonine } \\
\text { kinase }\end{array}$ \\
\hline NRAS & NRAS proto-oncogene \\
\hline MLH1 & DNA mismatch repair protein Mlh1 \\
\hline MSH2 & DNA mismatch repair protein Msh2 \\
\hline MSH6 & DNA mismatch repair protein Msh6 \\
\hline PMS2 & Mismatch repair endonuclease PMS2 \\
\hline WES & Whole exome sequencing \\
\hline NCOR1 & Nuclear receptor corepressor 1 gene \\
\hline TP53 & Tumor protein p53 gene \\
\hline SOS1 & $\begin{array}{l}\text { Ras/Rac guanine nucleotide exchange factor } \\
1 \text { gene }\end{array}$ \\
\hline APC & $\begin{array}{l}\text { adenomatosis polyposis coli, WNT signaling } \\
\text { pathway regulator gene }\end{array}$ \\
\hline
\end{tabular}

This is the author manuscript accepted for publication and has undergone full peer review but has not been through the copyediting, typesetting, pagination and proofreading process, which may lead to differences between this version and the Version of Record. Please cite this article as doi:

$10.1002 / \mathrm{pbc} .27362$.

This article is protected by copyright. All rights reserved. 


\section{Abstract}

Noonan syndrome (NS) is a developmental syndrome caused by germline mutations in the Ras signaling pathway. No association has been shown between NS and pediatric colorectal cancer (CRC). We report the case of CRC in a pediatric patient with NS. The patient underwent whole genome sequencing. A germline SOS1 mutation c.1310T>C (p. lle437Thr) confirmed NS diagnosis. No known hereditary cancer syndromes were identified. Tumor analysis revealed two mutations: a TP53 missense mutation c.481G>A (p. Ala161Tyr) and NCOR1 nonsense mutation c.6052C>T (p. Arg2018*). This report highlights the complexity of Ras signaling and the interplay between developmental syndromes and cancer.

Introduction

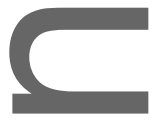

Introduction

Noonan syndrome (NS) is a developmental syndrome with an estimated prevalence of 1 in 1000-2500 and characterized by craniofacial abnormalities, cardiac defects, and cognitive delay. ${ }^{1}$ NS is caused by germline mutations affecting the Ras signaling pathway, as are neurofibromatosis 1 (NF1) and several other syndromes that are collectively referred to as Rasopathies. $^{2}$

The Ras signaling pathway is a ubiquitous intracellular signaling pathway that has been shown to play a central role in the pathogenesis of adult colorectal cancer (CRC). Interestingly, Rasopathies carry an inconsistent cancer predisposition ranging from an elevated risk of neurologic-type tumors in children with NF1 to a mild, almost exclusive risk for hematologic malignancies in Noonan syndrome patients of all ages. ${ }^{3-5}$ Germline mutations affecting Ras signaling pathway proteins have not been reported to carry a predisposition to colorectal cancer. Only 3 cases of Noonan syndrome patients with colorectal cancer have ever been reported and none in the pediatric population. ${ }^{3}$ 
Many of the same somatically mutated genes identified to cause adult CRC have been shown to be mutated in the germline of several cancer-predisposition syndromes. However, these syndromes account for the minority of pediatric CRC cases. ${ }^{6,7}$ Here we report the first report of pediatric colorectal cancer in a Noonan syndrome patient and the first wholegenome analysis of pediatric colorectal cancer.

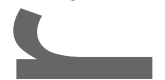

Clinical Course and Methods

A 14 year old female with Noonan syndrome presented with a four week history of nausea, vomiting, abdominal pain, and persistent constipation. CT of the abdomen and pelvis, and barium enema demonstrated complete large bowel obstruction with transition point at the sigmoid colon (Supplemental Figure S1). The patient was admitted, sigmoidoscopy revealed the site of the obstruction to be $35 \mathrm{~cm}$ from the anus, and then taken to the operating room. Exploratory laparotomy revealed an obstructing colonic mass in the sigmoid colon that was resected. Lymph nodes and observed omental and pelvic peritoneal lesions were biopsied. A diverting end-colostomy was made.

Pathology of the surgical specimens showed colon adenocarcinoma, stage T4aN2aM1 with low grade differentiation. Lymphovascular and perineural invasion was seen. Several lymph nodes (4 of 29) were positive for disease, three with extracapsular extension. Metastatic adenocarcinoma was observed in the omentum and in a pelvic peritoneal lesions.

Initial genetic testing for the three major known types of inherited colorectal cancer found no mutations associated with mismatch repair, APC, or MUTYH genes. BRAF V600 mutation and NRAS extended analyses were also negative. A KRAS gene mutation (c.38G $>A$ ) was present in the colonic mass, a contraindication to EGFR inhibitor therapy. The patient was then enrolled in PEDS-MI-ONCOSEQ, a prospective integrative clinical sequencing that has been approved by our institutional review board. ${ }^{8}$ The patient's parents provided informed consent and received mandatory pre-enrollment genetic counseling. 
Specifics of the PEDS-MI-ONCOSEQ sequencing procedure and bioinformatics analyses have been described previously (Supplemental Material S1). ${ }^{8}$ Nucleic acid preparation and high-throughput sequencing were performed using standard the Clinical Laboratory Improyement Amendments (CLIA) protocols. Pathogenicity of germline variants was determined through a review of the published literature and databases.

The patient received induction chemotherapy with 6 cycles of folinic acid (400 mg/m2), 5 fluorouracil (400 mg/m2, then $2400 \mathrm{mg} / \mathrm{m} 2$ over 46 hours), and oxaliplatin ( $85 \mathrm{mg} / \mathrm{m} 2$ ) combination chemotherapy with bevacizumab $(5 \mathrm{mg} / \mathrm{kg})$. Chemotherapy was administered every 2 weeks. Oxaliplatin was discontinued after 6 cycles. CT scans of the neck, chest, abdomen, and pelvis showed no evidence of metastasis.

The patient continued a maintenance chemotherapy regimen of folinic acid, 5fluorouracil, and bevacizumab every two weeks and did not receive radiation therapy. The patient relapsed at cycle 37, presenting with a small bowel obstruction, renal insufficiency and bilateral hydronephrosis. CT and PET imaging suggested progression of disease corresponding to these site of the pelvic lesion and suspected disease in Hartmann's pouch, uterine wall and bladder wall. The small bowel obstruction resolved and the hydronephrosis improved with the placement of bilateral ureteral stents. The family declined biopsy. The patient was treated with irinotecan $180 \mathrm{mg} / \mathrm{m} 2$ every 2 weeks and palliative measures to maximize quality of life. The patient received 3 doses of irinotecan, but despite a lack of irinotecan induced diarrhea the patient began experiencing worsening symptoms of ileus. At time of manuscript submission, the patient was managed in hospice care.

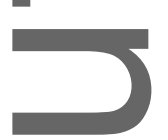

Results and Discussion

Integrative clinical sequencing revealed 3 mutations with clinical significance, one in the germline and two somatic mutations in the tumor sample (Table 1). Four somatic point mutations were also identified in the tumor sample (Supplemental Table S1). No CNV focal 
amplification or deletions detected, somatic insertion/deletion mutations, driving gene fusions, outlier expressions, or pathogens were detected.

SOS1 is an important Ras pathway regulator as a guanine nucleotide exchange factor (GEF). A SOS1 missense mutation c.1310T>C (p. lle437Thr) was identified in the germline, inducing an amino acid substitution (I437Y) near the plekstrin homology domain (aa 444548) (Supplemental Figure S2). This mutation has been previously reported as pathogenic for Noonan syndrome. ${ }^{9}$ Of note, SOS1 loss of heterozygosity was also demonstrated in the tumor. Despite playing an important role in Ras signaling, SOS1 has been shown to be insignificant in the development of cancer. ${ }^{10}$

p53, the protein product of TP53, has a well described importance in tumor suppression, with more than half of all sporadic human cancers demonstrating p53 mutations ${ }^{11}$ A TP53 missense mutation c.481G >A (p. Ala161Tyr) was identified in the tumor. This induces an amino acid substitution (A161Y) within the DNA-binding domain (aa 102-292) (Supplemental Figure S2). More than $80 \%$ of TP53 mutations in human tumors localize to the DNA-binding domain. ${ }^{12}$ Of note, germline TP53 mutations cause Li-Fraumeni syndrome (LFS) which carries a very high susceptibility to cancer. However, LFS is present in only $1.3 \%$ of early onset CRC cases. ${ }^{12,13}$

NCOR 1 is the cornerstone of an epigenetic complex that affects cell differentiation in several cell types via modulation of chromatin histone deacetylation. ${ }^{14}$ A NCOR1 somatic nonsense mutation c.6052C>T (p. Arg2018*) was identified, causing significant protein truncation (Supplemental Figure S2). The C-terminal end of NCOR1 contains two separate nuclear reeeptor-interacting domains, ID1 (aa 2032-2115) and ID2 (aa 2212-2273). Motifs within these regions have been shown to be necessary for binding to nuclear hormone receptors. NCOR1 also plays an important role in acute promyelocytic leukemia therapy. Retinoic acid competes with NCOR1 for transcription factor RAR alpha binding. ${ }^{15}$ Recently large scale genomic studies have identified NCOR1 driver mutations in breast cancer and hepatocarcinoma. ${ }^{16,17}$ 
Of note, no mutations affecting the Wnt signaling pathway were identified in the germline or the tumor. The Wnt pathway plays an important pathogenic role in $\mathrm{CRC}$, with $93 \%$ of all CRC tumors contain mutations affecting this pathway. ${ }^{6,11}$ Germline mutations in this pathway cause hereditary colorectal cancer syndromes including familial adenomatous polyposis (FAP) and juvenile polyposis.

The genetics of developmental syndromes have offered important insight into cancer, and the overlapping manifestations been described as a continuous spectrum (Figure 1). 6,7,18,19 Variations in genotype likely disrupt development by affecting the interplay between different signal transduction and epigenetic pathways. Subsequent compensation may explain survival as well as non-intuitive cancer risks. ${ }^{2,18-20}$ With the advancement of genetic testing and tissue pipelines, future whole-genome studies could identify the pathway changes of therapeutic value.

Conflict of interests

The authors declare that they have no competing interests.

\section{Funding}

The PEDS-MI-ONCOSEQ program is part of the MI-ONCOSEQ study at the University of Michigan Comprehensive Cancer Center. The MI-ONCOSEQ study is funded by the NIH Clinical Sequencing Exploratory Research (CSER) Award NIH 1UM1HG006508. Additional funding is provided by the Stand Up to Cancer-Prostate Cancer Foundation's Prostate Dream Team Translational Cancer Research Grant and the University of Michigan Comprehensive Cancer Center.

Ethics approval and consent to participate 
Written informed consent was obtained from the patient for publication of this case report and accompanying images. A copy of the written consent is available for review by the Editor-in-Chief of this journal on request.

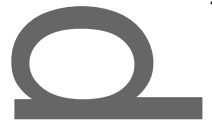

Authors' contributions

RMP participated in the procedure and postoperative care, collected clinical data, performed the literature search, and prepared the manuscript; RJM managed postoperative care, collected clinical data, participated in manuscript revision and conducted final review; MM, and ZN managed postoperative care, collected clinical data and participated in manuscript revision; GM was the assisting surgeon, participated in manuscript revision; JDG was the lead surgeon who conducted the procedure, participated in manuscript revision and conducted final review. All authors read and approved the final manuscript.

Acknowledgements

The authors thank the surgical nursing team for their essential assistance in post-operative management and the members of the University of Michigan Precision Medicine Tumor

Board for their support.

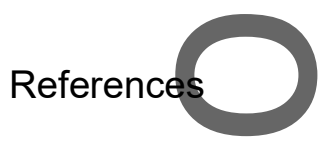

1. Roberts AE, Allanson JE, Tartaglia M, Gelb BD. Noonan syndrome. Lancet. 2013;381(9863):333-342.

2. Schubbert S, Shannon K, Bollag G. Hyperactive Ras in developmental disorders and cancer. Nat Rev Cancer. 2007;7(4):295-308.

3. Jongmans $\mathrm{MC}$, van der Burgt I, Hoogerbrugge $\mathrm{PM}$, et al. Cancer risk in patients with Noonan syndrome carrying a PTPN11 mutation. Eur J Hum Genet. 2011;19(8):870-874.

4. Kratz $\mathrm{CP}$, Franke $\mathrm{L}$, Peters $\mathrm{H}$, et al. Cancer spectrum and frequency among children with Noonan, Costello, and cardio-facio-cutaneous syndromes. Br J Cancer. 2015;112(8):1392-

5. Kratz CP, Rapisuwon S, Reed H, Hasle H, Rosenberg PS. Cancer in Noonan, Costello, cardiofaciocutaneous and LEOPARD syndromes. Am J Med Genet C Semin Med Genet. 2011;157C(2):83-89.

6. Carethers JM, Jung BH. Genetics and Genetic Biomarkers in Sporadic Colorectal Cancer. Gastroenterology. 2015;149(5):1177-1190 e1173. 
7. Vogelstein B, Papadopoulos N, Velculescu VE, Zhou S, Diaz LA, Jr., Kinzler KW. Cancer genome landscapes. Science. 2013;339(6127):1546-1558.

8. Mody RJ, Wu YM, Lonigro RJ, et al. Integrative Clinical Sequencing in the Management of Refractory or Relapsed Cancer in Youth. JAMA. 2015;314(9):913-925.

9. Lepri F, De Luca A, Stella L, et al. SOS1 mutations in Noonan syndrome: molecular spectrum, structural insights on pathogenic effects, and genotype-phenotype correlations. Hum Mutat. 2011;32(7) $2760-772$.

10. Swanson KD, Winter JM, Reis $\mathrm{M}$, et al. SOS1 mutations are rare in human malignancies: implications for Noonan Syndrome patients. Genes Chromosomes Cancer. 2008;47(3):253259.

11. Cancer Genome Atlas N. Comprehensive molecular characterization of human colon and rectal cancer. Nature. 2012;487(7407):330-337.

12. Bieging KT, Mello SS, Attardi LD. Unravelling mechanisms of p53-mediated tumour suppression. Nat Rev Cancer. 2014;14(5):359-370.

13. Yurgelun MB, Masciari S, Joshi VA, et al. Germline TP53 Mutations in Patients With EarlyOnset Colorectal Cancer in the Colon Cancer Family Registry. JAMA Oncol. 2015;1(2):214221

14. Martinez-Iglesias OA, Alonso-Merino E, Gomez-Rey S, et al. Autoregulatory loop of nuclear corepressor 1 expression controls invasion, tumor growth, and metastasis. Proc Natl Acad Sci U SA. 2016;113(3):E328-337.

15. Wong MM, Guo C, Zhang J. Nuclear receptor corepressor complexes in cancer: mechanism, function and regulation. Am J Clin Exp Urol. 2014;2(3):169-187.

16. Fujimoto A, Furuta $\mathrm{M}$, Totoki $\mathrm{Y}$, et al. Whole-genome mutational landscape and characterization of noncoding and structural mutations in liver cancer. Nat Genet. 2016;48(5):500-509.

17. Nik-Zainal S, Davies H, Staaf J, et al. Landscape of somatic mutations in 560 breast cancer whole-genome sequences. Nature. 2016;534(7605):47-54.

18. Bellacosa A. Developmental disease and cancer: biological and clinical overlaps. Am J Med Genet A. 2013;161A(11):2788-2796.

19. Kato S, Lippman SM, Flaherty KT, Kurzrock R. The Conundrum of Genetic "Drivers" in Benign Conditions. J Nat/ Cancer Inst. 2016;108(8).

20. Mendoza MC, Er EE, Blenis J. The Ras-ERK and PI3K-mTOR pathways: cross-talk and compensation. Trends Biochem Sci. 2011;36(6):320-328.

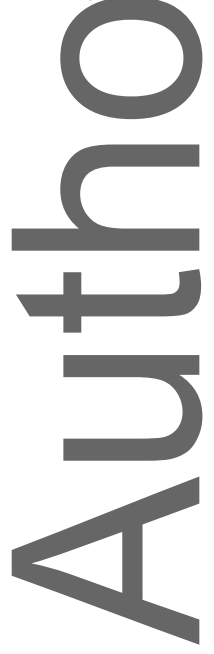

This article is protected by copyright. All rights reserved. 


\section{Table 1. Clinically significant mutations identified from genome-wide analysis}

Three point mutations with clinical significance were identified, one germline mutation and two somatic mutations in the tumor sample. The germline mutation in SOS1 and somatic mutation in TP53 encoded missense mutations causing a single amino acid change in the protein product. The somatic mutation in NCOR1 encoded a nonsense mutation causing a truncation of the protein product.

\begin{tabular}{|c|c|c|c|c|c|c|c|}
\hline Gene & Variant type & $\begin{array}{l}\text { Genome } \\
\text { locus }\end{array}$ & Exon & $\begin{array}{l}\text { Nucleotide } \\
\text { change }\end{array}$ & $\begin{array}{l}\text { Amino } \\
\text { acid } \\
\text { change }\end{array}$ & $\begin{array}{l}\text { Normal } \\
\text { protein } \\
\text { function }\end{array}$ & $\begin{array}{l}\text { Clinical } \\
\text { significance }\end{array}$ \\
\hline SOS1 & Germline & $2 \mathrm{p} 22.1$ & 10 & T1310C & Ile437Thr & $\begin{array}{l}\text { Guanine } \\
\text { exchange } \\
\text { factor, Ras } \\
\text { signaling }\end{array}$ & $\begin{array}{l}\text { Diagnostic } \\
\text { mutation for } \\
\text { Noonan } \\
\text { syndrome } 24\end{array}$ \\
\hline TP53 & atic & $17 p 13.1$ & 4 & G481A & Ala161Tyr & $\begin{array}{l}\text { Tumor } \\
\text { suppressor }\end{array}$ & $\begin{array}{l}>80 \% \text { of } \\
\text { TP53 } \\
\text { mutations in } \\
\text { human } \\
\text { tumors } \\
\text { localize to the } \\
\text { DNA binding } \\
\text { domain. }{ }^{22}\end{array}$ \\
\hline NCOR1 & Somatic & $17 p 11.2$ & 39 & C6052T & Arg2018* & $\begin{array}{l}\text { Transcriptio } \\
\text { nal } \\
\text { coregulator } \\
\text { y protein }\end{array}$ & $\begin{array}{l}\text { ID1 domain } \\
\text { dictates } \\
\text { retinoic acid } \\
\text { sensitivity in } \\
\text { APL } 31 \\
\text { NCOR } 1 \\
\text { mutations } \\
\text { may predict } \\
\text { tamoxifen } \\
\text { resistance in } \\
\text { breast cancer } \\
45\end{array}$ \\
\hline
\end{tabular}

This article is protected by copyright. All rights reserved. 
Figure 1. Overlap of developmental disease and cancer. A continuous clinical spectrum has been hypothesized to link genetic developmental syndromes and cancer predisposition, with developmental phehotypes possibly reflecting compensatory signaling changes. With permission from Bellacosa 2013, AJMG.
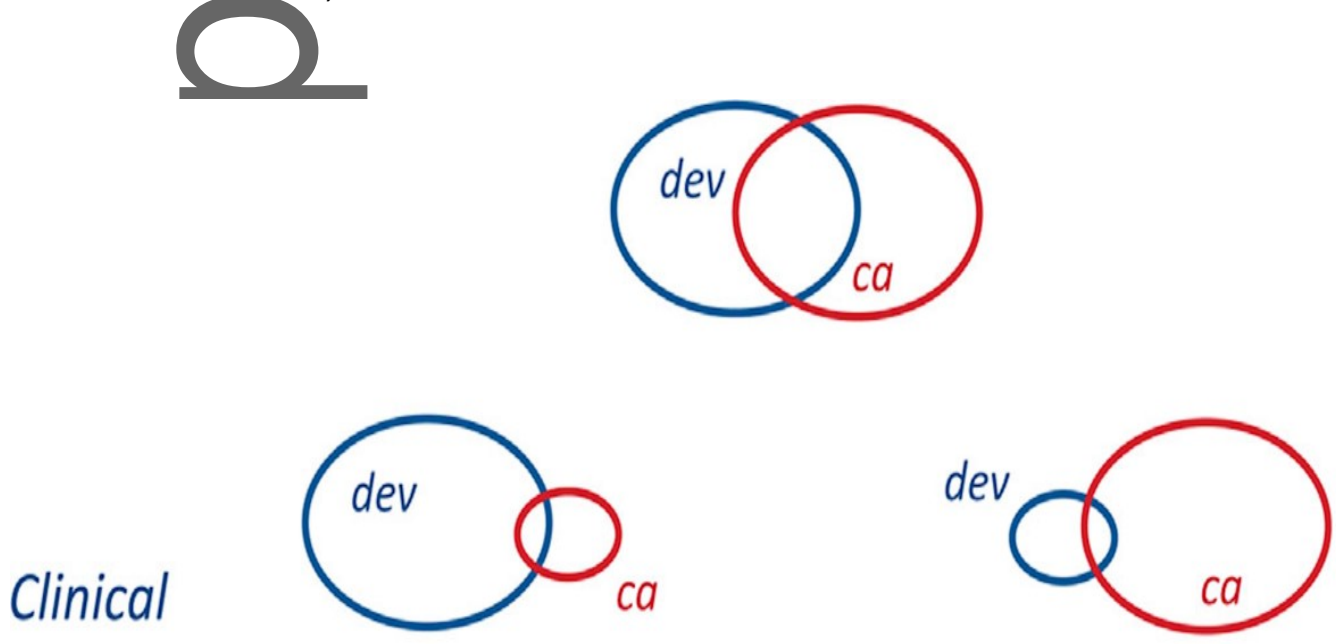

Clinical

Genetics

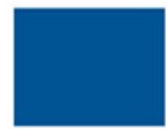

\section{continuous clinical spectrum}

Cohesinopathies

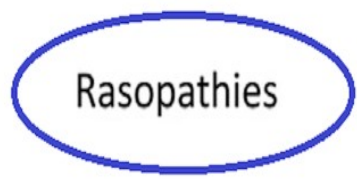

Dominant Cancer Syndromes

Recessive Chromosome

Breakage Syndromes

Phakomatoses

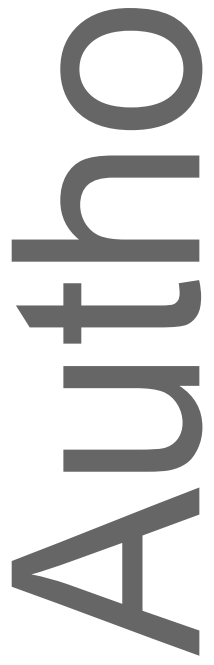

This article is protected by copyright. All rights reserved. 